\title{
Lifetime alcohol consumption and breast cancer: a case-control study in Finland
}

\author{
Satu Männistö ${ }^{1, *}$, Mikko Virtanen ${ }^{1}$, Vesa Kataja ${ }^{2}$, Matti Uusitupa $^{3}$ and Pirjo Pietinen ${ }^{1}$ \\ ${ }^{1}$ National Public Health Institute, Department of Nutrition, Mannerheimintie 166, 00300 Helsinki, Finland: \\ ${ }^{2}$ Kuopio University Hospital, Department of Oncology, 70211 Kuopio, Finland: ${ }^{3}$ University of Kuopio, \\ Department of Clinical Nutrition, 70211 Kuopio, Finland
}

Submitted 9 March 1999: Accepted 6 July 1999

\begin{abstract}
Objective: To study the association between lifetime alcohol consumption and the risk of breast cancer.

Design and setting: A case-control study carried out in eastern Finland. Information about alcohol consumption was obtained by two methods: a self-administered food frequency questionnaire (FFQ) including alcohol consumption during the previous 12 months, and a lifetime alcohol consumption questionnaire (AQ) which was administered by the study nurse.

Subjects: The study consisted of 301 breast cancer cases (25-75 years old) and 443 population controls.

Results: The subjects reported higher current alcohol consumption in the AQ compared to the FFQ. According to the AQ, premenopausal cases consumed on average $28 \mathrm{~g}$ and controls $24 \mathrm{~g}$ alcohol week ${ }^{-1}$; in postmenopausal women the values were 15 and $14 \mathrm{~g}$, respectively. About 30\% of premenopausal and 60\% of postmenopausal women were classified as non-drinkers. The correlation for current alcohol consumption between the FFQ and the AQ was 0.80 in premenopausal women but only 0.40 in postmenopausal women. Current alcohol consumption seemed to influence the reporting of total lifetime alcohol consumption. Current alcohol consumption was not associated with the risk of breast cancer either in premenopausal or postmenopausal women; neither were associations found between alcohol consumption at age of first use, use before the age of 30 , or total lifetime alcohol consumption and the risk of breast cancer.

Conclusions: On average, one to three drinks per week did not increase the risk of breast cancer in this study. Consumption levels were, however, too low to exclude increased risk with high regular consumption. Further research is necessary on lifetime alcohol consumption.
\end{abstract}

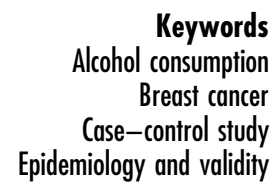

consumption Breast cancer Epidemiology and validity

\begin{abstract}
Alcohol consumption has been positively, although rather weakly, associated with breast cancer incidence and mortality in epidemiological studies, as reviewed by Longnecker ${ }^{1}$. No final agreement, however, has been found because results for premenopausal and postmenopausal women are inconclusive, and because there is no clear evidence of a dose-response relationship. Instead, a large range of threshold values (between 5 and $60 \mathrm{~g}$ alcohol day $^{-1}$ ) has been presented ${ }^{2,3}$. In a meta-analysis of six case-control studies ${ }^{4}$, a statistically significant increased risk of breast cancer was found for women who consumed at least $40 \mathrm{~g}$ alcohol day ${ }^{-1}$. The result has been confirmed in a pooled analysis of six prospective studies including 4335 breast cancer cases diagnosed from a total of 322647 premenopausal and postmenopausal women $^{5}$. In that study, the risk of breast cancer increased when alcohol intake was over $30 \mathrm{~g} \mathrm{day}^{-1}$. Often within one country, the most consumed alcohol beverage has had the
\end{abstract}

strongest relation with the risk of breast cancer. Thus, pure alcohol may be more important for assessing the risk of breast cancer than any specific alcoholic beverage ${ }^{4}$.

Increased endogenous oestrogen has been suggested as a potential mechanism by which alcohol could increase breast cancer risk. In a controlled crossover trial ${ }^{6}$, plasma and urinary oestrogen concentrations increased in premenopausal women who consumed $30 \mathrm{~g}$ alcohol day $^{-1}$. Alcohol may also induce free radical production, act as a tumour promoter, increase the proliferation of mammary cells and have an influence on immune response $^{7}$. Furthermore, high alcohol consumption increases abdominal obesity, which has been found to be a possible risk factor for breast cancer ${ }^{8}$.

In the aetiology of breast cancer, exposure to dietary factors early in life may be more important than current consumption, but their implications in the risk are difficult to show. Only a few studies have examined the association 
of alcohol consumption and breast cancer between puberty and the first pregnancy when hormonal metabolism changes the most, and the results have been inconclusive ${ }^{9-11}$. High total lifetime alcohol consumption was associated with increased risk of breast cancer in a large case-control study in New York ${ }^{12}$. The subject's ability to recall their past alcohol consumption, however, is the key question in these kind of studies, as has been shown by research in New York ${ }^{11}$ and Sweden ${ }^{13}$. To evaluate the effect of alcohol on the risk of breast cancer comprehensively, there is an apparent need for studies on past alcohol consumption, cumulative lifetime alcohol consumption and the pattern of alcohol consumption in different populations ${ }^{14}$.

We examined the association between current alcohol consumption and breast cancer risk by comparing two types of methods: a validated self-administered FFQ and a detailed, interview-based questionnaire on lifetime alcohol consumption. We also examined alcohol consumption during different time periods (at age of first use, before the age of 30 years and cumulative lifetime alcohol consumption) using the AQ.

\section{Subjects and methods}

\section{Subjects}

The Kuopio Breast Cancer Study, which is a case-control study, has been conducted in eastern Finland within the framework of the International Collaborative Study of Breast and Colorectal Cancer coordinated by the European Institute of Oncology in Milan. The Joint Ethics Committee of Kuopio University and Kuopio University Hospital gave approval for the study, and all subjects gave their written consent.

The study participants were 25-75-year-old women who lived in the catchment area of the Kuopio University Hospital and were referred to the hospital for a breast examination between October 1990 and December 1995, subsequently being diagnosed with breast cancer. Each patient was interviewed by the trained study nurse before any diagnostic procedures. Healthy population controls were drawn from the National Population Register and were individually matched with the cases according to area of residence (rural/urban) and age ( \pm 5 years). A FFQ was mailed to the subjects with the referral letter. The subjects were asked to complete the questionnaire at home and return it to the study nurse. Body mass index and waist-to-hip ratio were also measured during the interview, and information on personal characteristics and habits (smoking and physical activity), socioeconomic status, medical history, family history of breast cancer and reproductive factors were asked in a structured questionnaire.

The alcohol study included 113 premenopausal and 188 postmenopausal cases with histologically confirmed breast cancer. In all, 172 premenopausal and 271 postmenopausal controls were interviewed similarly as the cases. The number of controls was higher than cases because more than one control was selected for each case during the first study year. The participation rate of the controls was $72 \%$. Exclusions due to unwillingness to participate, inability to cooperate, the presence of another serious disease, or a missing or unacceptable FFQ, as well as the summary of selected characteristics of the study population have been presented earlier ${ }^{15}$. Additionally, 12 premenopausal (six cases and six controls) and eight postmenopausal women (three cases and five controls) were excluded because of a missing AQ. The associations between the known risk factors and the risk of breast cancer were similar to findings from earlier studies ${ }^{16}$.

\section{Food frequency questionnaire}

The semiquantitative FFQ, which concentrated on habitual consumption of foods and beverages over the previous 12 months, was mailed to the women with the referral letter to the Kuopio University Hospital. The usual consumption of 110 food items and mixed dishes were recorded using nine frequency categories from 'never' to 'six or more times a day'. The alcohol items included beer, long-drink (a special alcohol beverage in Finland), wine, fortified wine and spirits, which together covered all types of alcoholic beverages consumed.

Individual absolute alcohol intake $\left(\mathrm{gweek}^{-1}\right)$ was computed employing the food composition database of the National Public Health Institute ${ }^{17}$. The reproducibility and validity of the FFQ were tested in 152 population controls ${ }^{18}$. The intraclass correlation between the first and second FFQ was 0.64 for alcohol. When the FFQ was validated against a 14-day diet record, the Pearson correlation coefficient for alcohol was 0.80 . The subjects were divided into four alcohol consumption groups: those who reported no alcohol consumption $(0 \mathrm{~g})$ during the past year were classified as abstainers, and alcohol consumers were divided into three categories (tertiles) according to alcohol intake.

\section{Alcobol questionnaire}

The questionnaire of lifetime alcohol consumption was filled in during the interview between the study nurse and the subject. In the AQ it was possible to describe intervals at which alcohol was consumed (age at start and end), portion and frequency (daily, weekly, monthly or yearly) separately for beer, long-drink, wine, fortified wine and spirits. The subjects were allowed to define as many drinking intervals as needed. Alcohol drinkers were especially asked to recall all special events in their life that were likely to be associated with changes in alcohol consumption, for example, leaving the parental home, births of children, divorce and unemployment. The maximum number of drinking intervals reported was between two and five depending on the alcoholic beverage. One portion of alcohol (e.g. a bottle of beer, a 
glass of wine) was defined to contain on average $12 \mathrm{~g}$ ethanol.

The following variables were determined from the AQ: current consumption of alcohol $\left(\mathrm{g} \mathrm{week}^{-1}\right)$, age at first use (year), alcohol consumption during the first year alcohol was consumed $\left(\mathrm{g}_{\text {week }}{ }^{-1}\right)$, total alcohol consumption before the age of 30 (cumulative sum of all alcohol) and total lifetime alcohol consumption (cumulative sum). As in the FFQ, abstainers formed their own category, but exdrinkers were separated from abstainers when current alcohol consumption was examined. Alcohol consumers were divided into three categories using tertiles, with the exception of total consumption before the age of 30 , which was dichotomized into two groups of alcohol consumers using the median as the cut-off point. In this paper, the terms 'alcohol consumption' and 'alcohol intake' refer to absolute alcohol intake, and alcohol consumers are all those subjects who consumed alcohol, regardless of beverage types.

\section{Statistical methods}

Individual matching for area of residence (rural/urban) and age (within \pm 5 years) were used to avoid skewed distributions of these variables in the cases and the controls. Since this matching, however, was quite permissive, group matching was used in the analyses.

The validity between the FFQ and the AQ was compared by the Pearson correlation coefficient. To measure the degree of misclassification, subjects were categorized by alcohol consumption into four groups (abstainers and tertiles of alcohol consumers), based on both methods. The proportions of subjects that were equally categorized by both methods were calculated.

The risk of breast cancer was estimated by an odds ratio. The models were adjusted for known risk factors for breast cancer, in other words, age, area of residence (rural/ urban), age at menarche, age at first full-term pregnancy, use of oral contraceptives, use of oestrogen replacement therapy, family history of breast cancer, history of benign breast disease, level of education, smoking, physical activity, body mass index and waist-to-hip ratio. Since $\log$ transformation and energy adjustment did not affect the results for current alcohol consumption ${ }^{19}$, only the results without these adjustments are presented. Further, to take into account the decreasing recall of past alcohol consumption, alcohol consumption at the age of first use and total lifetime alcohol consumption were adjusted for the duration between the age at the interview and the age at first alcohol use. The total alcohol consumption before the age of 30 years was adjusted for the duration between the age at interview and age 30 .

\section{Results}

A good agreement between the reported current alcohol consumption measured by the FFQ and by the AQ ( $r=$ 0.80 ) was found in premenopausal women (Table 1). The agreement was, however, not so convincing for postmenopausal women $(r=0.40)$. For all women, total lifetime alcohol consumption correlated well with current alcohol consumption $(r=0.74)$.

The subjects were divided into alcohol categories (nondrinkers and tertiles of alcohol consumption) according to the FFQ and the AQ (Table 2). In all, 64\% (181) of premenopausal and 70\% (323) of postmenopausal women were classified into the same category by both methods. Nine lifetime non-drinkers or ex-drinkers measured by the AQ were classified into the highest alcohol tertile of the FFQ, and one heavy drinker based on the AQ was classified as a non-drinker in the FFQ. All these 10 clearly misclassified women were postmenopausal.

Current alcohol consumption was higher in premenopausal women than in postmenopausal women based on both methods. The subjects reported somewhat higher consumption of alcohol in the AQ than in the FFQ. In the $\mathrm{FFQ}$, the unadjusted mean alcohol intake was $24 \mathrm{~g}$ week $^{-1}$ for premenopausal cases and $21 \mathrm{~g} \mathrm{week}^{-1}$ for controls (for alcohol drinkers only, the intake was 37 and $30 \mathrm{~g}$, respectively). Postmenopausal cases consumed on average $9 \mathrm{gweek}^{-1}$ and controls $14 \mathrm{gweek}^{-1}$ (for alcohol drinkers only, the intake was 19 and $29 \mathrm{~g}$, respectively). In the $\mathrm{AQ}$, the mean alcohol intake was $28 \mathrm{~g} \mathrm{week}^{-1}$ for premenopausal cases and $24 \mathrm{gweek}^{-1}$ for controls (for alcohol drinkers only, 40 and $33 \mathrm{~g}$, respectively). The means for postmenopausal women were $15 \mathrm{~g} \mathrm{week}^{-1}$ for cases and $14 \mathrm{~g} \mathrm{week}^{-1}$ for controls (for alcohol drinkers only, 38 and $33 \mathrm{~g}$, respectively). The difference between alcohol intakes of cases and controls was statistically significant (age and area adjusted $P=0.03$ ) only for postmenopausal women measured by the FFQ. The number of premenopausal abstainers was higher in the FFQ than in the AQ, while the result was opposite in postmenopausal

Table 1 Pearson correlation coefficients between current and lifetime alcohol consumption

\begin{tabular}{lccc}
\hline & \multicolumn{2}{c}{ Current alcohol intake by $A Q$} \\
\cline { 2 - 4 } Alcohol indicator & $\begin{array}{c}\text { Premenopausal } \\
\text { women }\end{array}$ & $\begin{array}{c}\text { Postmenopausal } \\
\text { women }\end{array}$ & $\begin{array}{c}\text { All } \\
\text { women }\end{array}$ \\
\hline Current alcohol intake by FFQ & 0.80 & 0.40 & 0.60 \\
At age of first use by AQ & 0.46 & 0.48 & 0.48 \\
Before age 30 by AQ & 0.35 & 0.51 & 0.42 \\
Lifetime alcohol intake by AQ & 0.70 & 0.79 & 0.74 \\
\hline
\end{tabular}


Table 2 Number of subjects categorized into the same alcohol category according to the food frequency questionnaire (FFQ) and the questionnaire of lifetime alcohol consumption (AQ)

\begin{tabular}{|c|c|c|c|c|c|}
\hline & \multicolumn{5}{|c|}{ Current alcohol intake based on $A Q$} \\
\hline & $\begin{array}{l}\text { Lifetime } \\
\text { non-drinker }\end{array}$ & Ex-drinker & Tertile 1 & Tertile 2 & Tertile 3 \\
\hline \multicolumn{6}{|c|}{ Premenopausal women } \\
\hline \multicolumn{6}{|c|}{ Current alcohol intake based on FFQ } \\
\hline Non-drinker & 63 & 9 & 16 & 6 & 0 \\
\hline Tertile 1 & 4 & 1 & 33 & 18 & 4 \\
\hline Tertile 2 & 1 & 1 & 18 & 28 & 18 \\
\hline Tertile 3 & 0 & 0 & 1 & 16 & 48 \\
\hline \multicolumn{6}{|c|}{ Postmenopausal women } \\
\hline \multicolumn{6}{|c|}{ Current alcohol intake based on FFQ } \\
\hline Non-drinker & 215 & 10 & 11 & 5 & 1 \\
\hline Tertile 1 & 25 & 0 & 29 & 13 & 5 \\
\hline Tertile 2 & 6 & 5 & 20 & 26 & 15 \\
\hline Tertile 3 & 3 & 6 & 6 & 15 & 43 \\
\hline
\end{tabular}

women (Table 3). Of all premenopausal women, about $30 \%$ were classified as abstainers, while the percentage for postmenopausal women was over 50\%. In the AQ, it was possible to separate ex-drinkers from abstainers. The proportion of ex-drinkers was low, 3-4\% for premenopausal and 4-5\% for postmenopausal women.

Current alcohol consumption was not associated with breast cancer risk either in premenopausal or postmenopausal women - the odds ratios were around the value of 1.0 for all alcohol consumption categories (Table 3). The odds ratio, however, was 1.4 for the premenopausal ex-drinkers but the number of subjects was too low to confirm the risk. When the 10 clearly misclassified postmenopausal women were excluded from the analysis, the odds ratios based on the FFQ did not change notably: 1.0, 1.1 (95\%CI 0.6-2.0), $1.2(0.7-2.2)$ and $0.7(0.3-1.4)$ for each category (Table 3$)$. The association between current alcohol intake measured by the AQ and the risk of breast cancer in postmenopausal ex-drinkers, however, changed to $1.1(0.3-3.5)$, while the other risks were similar to the initial values.

Lifetime alcohol consumption by menopausal status is presented in Table 4. Most of the premenopausal alcohol consumers started to drink alcohol before 30 years of age, while most postmenopausal women started later. Those who started to drink alcohol before 30 years of age, however, had the same risk for breast cancer as the others. No evidence of any relation was found between the mean alcohol consumption at age of first use and the risk of premenopausal breast cancer. Instead, postmenopausal women who consume at most two drinks per month (under $7 \mathrm{~g} \mathrm{week}^{-1}$ ) may have a lower risk of breast cancer, as did women whose cumulative alcohol consumption before the age of 30 years was under the median. However, more data are needed to confirm these results. Further, no significant associations were found between cumulative lifetime alcohol consumption and the risk of premenopausal or postmenopausal breast cancer. Because the interpretation of results was similar when models were adjusted for the duration of alcohol use (data not shown), only the results adjusted for the known risk factors for breast cancer are presented.

\section{Discussion}

Based mostly on epidemiological studies, a modest positive association between alcohol intake and the risk of breast cancer has been found ${ }^{1,5}$. The causality between alcohol consumption and increased cancer risk, however, has been questioned because only a few cohort studies have found a clear dose-response relationship. Two large cohort studies, the Netherlands Cohort Study in postmenopausal women ${ }^{20}$ and the Canadian National Breast Screening Study in premenopausal women ${ }^{21}$, have indicated a threshold at around $30 \mathrm{~g}$ alcohol day ${ }^{-1}$ after which the risk of breast cancer increased $(R R=1.7$ and $\mathrm{RR}=1.9$, respectively). The cohort study by the American Cancer Society, the biggest cohort study thus far, including 580000 postmenopausal women, showed an increased breast cancer mortality rate $(\mathrm{RR}=1.9)$ above five drinks per day (about $60 \mathrm{~g}$ absolute alcohol) ${ }^{3}$. A lower threshold value ( $15 \mathrm{~g}$ alcohol $\mathrm{day}^{-1}$ ) was found in postmenopausal women in the Iowa Women's Health Study ${ }^{22}$ and in both premenopausal and postmenopausal women in the Nurses Health Study $\left(5 \mathrm{~g} \mathrm{day}^{-1}\right)^{2}$. In both of these studies, the relative risk was under 2 . On the other hand, no association between alcohol and the risk of breast cancer was found in the New York State Cohort ${ }^{5,23}$ and in the Sweden Mammography Cohort ${ }^{5,24}$. It also seems that the strength of the association between alcohol and breast cancer risk decreases with an increase in follow-up time ${ }^{1}$.

Howe et $a l .{ }^{4}$ found, in their meta-analysis of six casecontrol studies, an elevated risk of breast cancer for drinkers whose alcohol intake was at least $40 \mathrm{~g} \mathrm{day}^{-1}(\mathrm{OR}=1.7$, 95\%CI 1.2-2.4). Findings from combined studies on 38 cohort and case-control studies have also shown that the higher the alcohol consumption in the population the stronger the association ${ }^{1}$; the studies by Ferraroni et al. ${ }^{25}$ 


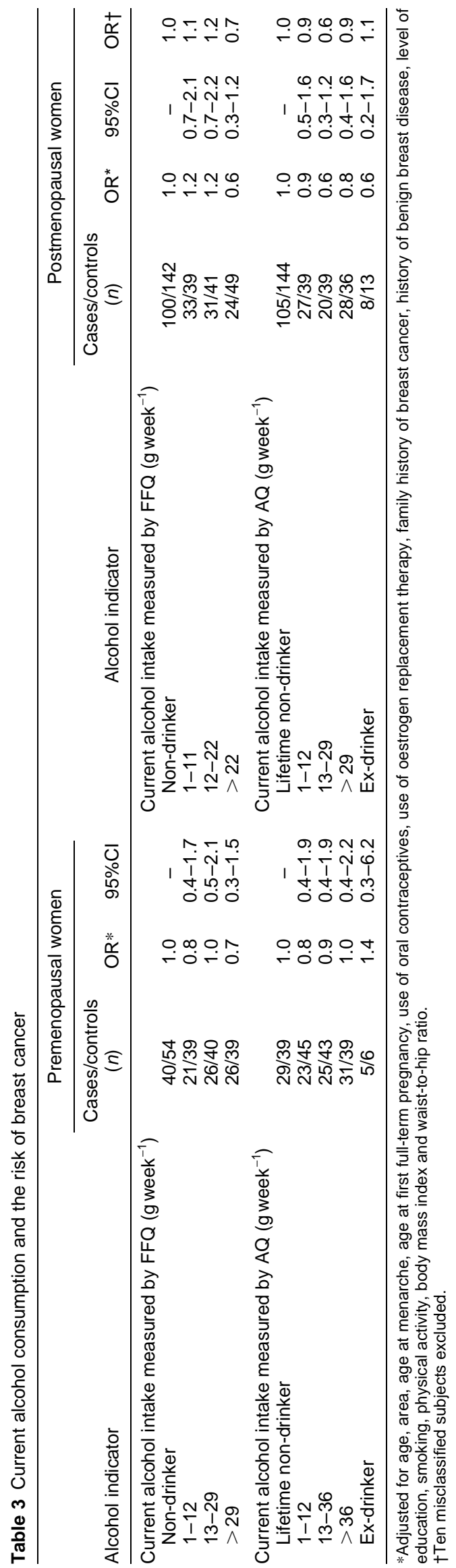

and Katsouyanni et ll $^{7}$ from southern Europe are good examples. A recent case-control study carried out in France, Switzerland, Northern Ireland, the Netherlands and Spain (the Euramic Study) found an increased breast cancer risk only for postmenopausal ex-drinkers ${ }^{26}$. The authors suspected that overall alcohol consumption was too low to rule out increased risk with high regular consumption.

Only a few studies have provided information on breast cancer risk in female alcoholics, and these studies have been criticized because of the small number of subjects, incompletely measured alcohol consumption and a poor control of major breast cancer risk factors in the analyses ${ }^{1}$. A doubling of breast cancer mortality rate in female alcoholics has been shown in a cohort study in the United Kingdom $^{27}$. A Swedish cohort study on breast cancer incidence (followed up for 19 years) did not find an increased risk for women with a diagnosis of alcoholism ${ }^{28}$.

In our study, current alcohol consumption measured by the FFQ or by the AQ was not associated with an increased risk of breast cancer either in premenopausal or postmenopausal women. The current alcohol intake, however, was quite low, about two drinks per week in premenopausal women and only one drink per week in postmenopausal women (based on the AQ). It is well known that Finnish postmenopausal women belong to a generation that has never consumed much alcohol. In population surveys of Finnish adults, 55-64-year-old women in the Kuopio province consumed an average of $3 \mathrm{~g}$ of alcohol week ${ }^{-1}$ in 1982 and $10 \mathrm{~g}$ in 1992, while the youngest women (25-34 years old) consumed $17 \mathrm{~g}$ alcohol week ${ }^{-1}$ in 1982 and $25 \mathrm{~g}$ in $1992^{29,30}$.

It is also possible that older women may underreport their alcohol consumption more than younger women because of negative moral attitudes in Finland. Our results support this view since alcohol reporting was more inaccurate in older than in younger women. Based on several surveys in Finland, alcohol consumption is generally underreported so that less than half the amount reported in official statistics is found ${ }^{31}$. Overall, the underestimation of alcohol consumption has been found to be more common in populations where alcohol consumption is low compared to those populations where drinking frequency is high and alcohol consumption at mealtimes is common. In a case-control study in Italy, where alcohol consumption is quite high, alcohol consumption was estimated as explaining $12 \%$ of breast cancer incidence ${ }^{25}$.

The validity of methods is an important issue. When the most important methods to assess alcohol consumption were reviewed (quantity, frequency, extended quantity frequency, retrospective diary, prospective diary and 24hour recall), the ranking of subjects according to alcohol consumption varied from $r=0.63$ to $r=0.73$ between methods $^{32}$. Several validation studies have found that alcohol is one of the most accurately measured dietary 
Table 4 Lifetime alcohol consumption and the risk of breast cancer

\begin{tabular}{|c|c|c|c|c|c|c|c|}
\hline \multirow[b]{2}{*}{ Alcohol indicator } & \multicolumn{3}{|c|}{ Premenopausal women } & \multirow[b]{2}{*}{ Alcohol indicator } & \multicolumn{3}{|c|}{ Postmenopausal women } \\
\hline & $\begin{array}{c}\text { Cases/controls } \\
(n)\end{array}$ & OR* & $95 \% \mathrm{Cl}$ & & $\begin{array}{c}\text { Cases/controls } \\
(n)\end{array}$ & OR* & $95 \% \mathrm{Cl}$ \\
\hline $\begin{array}{l}\text { Age at first use } \\
\text { Lifetime non-drinker } \\
<30 \text { years old } \\
\geqslant 30 \text { years old }\end{array}$ & $\begin{array}{l}29 / 39 \\
58 / 101 \\
26 / 32\end{array}$ & $\begin{array}{l}1.0 \\
0.8 \\
1.2\end{array}$ & $\begin{array}{c}- \\
0.4-1.6 \\
0.5-2.7\end{array}$ & $\begin{array}{l}\text { Age at first use } \\
\text { Lifetime non-drinker } \\
<30 \text { years old } \\
\geqslant 30 \text { years old }\end{array}$ & $\begin{array}{c}105 / 144 \\
27 / 49 \\
56 / 78\end{array}$ & $\begin{array}{l}1.0 \\
0.6 \\
0.8\end{array}$ & $\begin{array}{c}- \\
0.3-1.2 \\
0.5-1.3\end{array}$ \\
\hline $\begin{array}{l}\text { Alcohol intake at age of first use }\left(\mathrm{g} \mathrm{week}^{-1}\right) \\
\text { Lifetime non-drinker } \\
1-6 \\
7-25 \\
>25\end{array}$ & $\begin{array}{l}29 / 39 \\
26 / 47 \\
26 / 47 \\
32 / 39\end{array}$ & $\begin{array}{l}1.0 \\
0.8 \\
0.9 \\
1.1\end{array}$ & $\begin{array}{l}- \\
0.4-1.8 \\
0.4-1.9 \\
0.5-2.4\end{array}$ & $\begin{array}{l}\text { Alcohol intake at age of first use }\left(\mathrm{g} \mathrm{week}^{-1}\right) \\
\text { Lifetime non-drinker } \\
1-7 \\
8-21 \\
>21\end{array}$ & $\begin{array}{l}105 / 144 \\
18 / 52 \\
29 / 39 \\
36 / 36\end{array}$ & $\begin{array}{l}1.0 \\
0.4 \\
1.1 \\
1.1\end{array}$ & $\begin{array}{l}- \\
0.2-0.8 \\
0.6-2.0 \\
0.5-2.1\end{array}$ \\
\hline $\begin{array}{l}\text { Cumulative alcohol intake before age of } 30(\mathrm{~g}) \\
\text { Non-drinker }<30 \text { years } \\
1-7250 \\
>7250\end{array}$ & $\begin{array}{l}55 / 71 \\
23 / 56 \\
35 / 45\end{array}$ & $\begin{array}{l}1.0 \\
0.6 \\
0.9\end{array}$ & $\begin{array}{c}- \\
0.3-1.2 \\
0.4-1.9\end{array}$ & $\begin{array}{l}\text { Cumulative alcohol intake before age of } 30(\mathrm{~g}) \\
\text { Non-drinker }<30 \text { years } \\
1-3744 \\
>3744\end{array}$ & $\begin{array}{c}161 / 222 \\
11 / 28 \\
16 / 21\end{array}$ & $\begin{array}{l}1.0 \\
0.5 \\
1.0\end{array}$ & $\begin{array}{c}- \\
0.2-1.1 \\
0.4-2.4\end{array}$ \\
\hline $\begin{array}{l}\text { Cumulative lifetime alcohol intake }(\mathrm{g}) \\
\text { Lifetime non-drinker } \\
1-11155 \\
11155-28657 \\
>28657\end{array}$ & $\begin{array}{l}29 / 39 \\
26 / 47 \\
25 / 45 \\
33 / 41\end{array}$ & $\begin{array}{l}1.0 \\
0.9 \\
0.9 \\
0.9\end{array}$ & $\begin{array}{l}- \\
0.4-2.0 \\
0.4-1.9 \\
0.4-2.2\end{array}$ & $\begin{array}{l}\text { Cumulative lifetime alcohol intake }(\mathrm{g}) \\
\text { Lifetime non-drinker } \\
1-9360 \\
9361-28028 \\
>28028\end{array}$ & $\begin{array}{l}105 / 144 \\
26 / 45 \\
29 / 39 \\
28 / 43\end{array}$ & $\begin{array}{l}1.0 \\
0.7 \\
0.9 \\
0.6\end{array}$ & $\begin{array}{l}- \\
0.4-1.3 \\
0.5-1.7 \\
0.3-1.3\end{array}$ \\
\hline
\end{tabular}

*Adjusted for age, area, age at menarche, age at first full-term pregnancy, use of oral contraceptives, use of oestrogen replacement therapy, family history of breast cancer, history of benign breast disease, level of education, smoking, physical activity, body mass index and waist-to-hip ratio. 
factors. The question still remains whether the methods measure alcohol consumption well or whether they consistently measure consumption poorly, for example with underreporting. We used two methods for measuring alcohol consumption, the FFQ and the AQ. In our validation study of the FFQ, the reliability for alcohol consumption was 0.64 , and the validity between the first FFQ and a 14-day diet record was 0.80 . Further, $95 \%$ of subjects measured by the FFQ were categorized into the same or adjacent alcohol quintiles when the diet records were used ${ }^{18}$. The current alcohol consumption measured by the AQ was validated against the FFQ, and correlation was high for premenopausal women $(r=0.80)$. Reporting of alcohol consumption, however, was not so reliable in postmenopausal women $(r=0.40)$.

There is still a lack of data identifying the critical times in a woman's lifetime when exposure to alcohol is particularly relevant to breast cancer risk. Alcohol consumption has been assumed to be more harmful during puberty or pregnancy because of alterations in breast tissue ${ }^{33}$. Two recent studies have found no association between the age when alcohol consumption began and the risk of breast cancer ${ }^{11,34}$, while two studies reported a positive association ${ }^{9,35}$ and, a study in New York, found an inverse association ${ }^{10}$. Freudenheim et al. ${ }^{36}$ found that alcohol consumption at 16 years of age was not related to increased risk of premenopausal or postmenopausal breast cancer. Harvey et al. ${ }^{37}$ reported a similar elevation in breast cancer risk for women who consumed alcohol before the age of 30 but later stopped, as compared to those who continued to drink.

Longnecker et al. ${ }^{12}$ suggested that lifetime alcohol consumption would be the best indicator to evaluate the breast cancer risk associated with alcohol consumption. They showed - in a large case-control study conducted in Maine, Massachusetts, New Hampshire and Wisconsin - a dose-response association between lifetime alcohol consumption and the risk of breast cancer in 6163 cases and 8480 controls under the age of 75 years. A casecontrol study in New York found an increased risk of breast cancer in premenopausal and postmenopausal women who had consumed alcohol for more than 20 years. The relevance of duration of drinking, however, disappeared when both alcohol consumption per day and duration were simultaneously included in the model ${ }^{11}$. Those few studies reported thus far have typically asked about past alcohol consumption during 10-year intervals or at a specific age. In only one case-control study (other than this study), in Sweden, have the age periods not been fixed but the subjects were allowed to define drinking intervals by themselves ${ }^{13}$. In the Swedish study, premenopausal women in the highest category of cumulative alcohol consumption had a higher risk of breast cancer compared to those in the lowest category, but the association disappeared after adjustments for recent alcohol consumption. In our study, where subjects were also able to freely define their drinking intervals, no statistically significant association was found between past alcohol consumption (age at first use, consumption before the age of 30 and cumulative lifetime consumption) and the risk of premenopausal or postmenopausal breast cancer.

Swanson et al. ${ }^{13}$ concluded that past and total lifetime alcohol consumptions are not as relevant to the aetiology of breast cancer as current consumption. The key question, however, is the subjects' ability to recall their past alcohol consumption. Because it was not possible to evaluate the validity of past alcohol consumption in our study, we cannot be sure that poor recollection has not attenuated the risk estimates. Dwyer et al ${ }^{38}$ showed that alcohol consumption reported at the age of 30 correlated well $(r=0.78)$ with consumption recalled 20 years later when the subjects were studied again at the age of 50 . The validity of reporting, however, was not so accurate for alcohol consumption at age 18 years. In one study, the correlation between reported alcohol consumption as recalled 10 years back and the records from that time period was $0.7^{39}$. The authors also found that current drinking habits may influence the estimation of recalled alcohol consumption. In our study, the correlation between current alcohol consumption and cumulative lifetime consumption was also high, over 0.7 , both in premenopausal and postmenopausal women.

Our study showed that alcohol is not among the risk factors for breast cancer in eastern Finland; at least, one to three drinks per week did not increase the risk of breast cancer either in premenopausal or in postmenopausal women. Recommendations to reduce the incidence of cancer throughout the world by $30-40 \%$ suggest that alcohol consumption should be limited to one drink per day for women ${ }^{40}$. This recommendation takes into account the evidence that modest alcohol consumption is a protective factor for coronary heart disease. However, more information is required on the dose-response relationship between alcohol consumption and the risk of breast cancer, total lifetime alcohol consumption and underestimation of alcohol consumption in different populations. It is also important to evaluate the effect of alcohol consumption for the risk of breast cancer during the time span between menarche and the first full-term pregnancy.

\section{Acknowledgements}

This work was supported by EVO funds from Kuopio University Hospital and by research grants from the Academy of Finland, the Yrjö Jahnsson Foundation, the Juho Vainio Foundation and the Finnish Foundation for Alcohol Studies. We thank our colleagues at the Kuopio Cancer Research Centre and Annakaisa Lyytinen, RN, for interviewing the subjects. We are also grateful to Juha Javanainen, MSc, for his technical help. 


\section{References}

1 Longnecker MP. Alcoholic beverage consumption in relation to risk of breast cancer: meta-analysis and review. Cancer Causes Control 1994; 5: 73-82.

2 Willett WC, Stampfer MJ, Colditz GA, Rosner BA, Hennekens $\mathrm{CH}$, Speizer FE. Moderate alcohol consumption and the risk of breast cancer. N. Engl. J. Med. 1987; 316: 1174-80.

3 Garfinkel L, Boffetta P, Stellman SD. Alcohol and breast cancer: a cohort study. Prev. Med. 1988; 17: 686-93.

4 Howe G, Rohan T, Decarli A, et al. The association between alcohol and breast cancer risk: evidence from the combined analysis of six dietary case-control studies. Int. J. Cancer 1991; 47: 707-10.

5 Smith-Warner SA, Spiegelman D, Shiaw-Shyuan Y, et al. Alcohol and breast cancer in women. A pooled analysis of cohort studies. JAMA 1998; 279: 535-40.

6 Reichman ME, Judd JT, Longcope C, et al. Effects of alcohol consumption on plasma and urinary hormone concentrations in premenopausal women. J. Natl. Cancer Inst. 1993; 85: 722-7.

7 Katsouyanni K, Trichopoulou A, Stuver S, et al. Ethanol and breast cancer: an association that may be both confounded and causal. Int. J. Cancer 1994; 58: 356-61.

8 Seidell JC. Environmental influences on regional fat distribution. Int. J. Obesity 1991; 15: 31-5.

9 Van't Veer P, Kok FJ, Hermus RJ, Sturmans F. Alcohol dose, frequency and age at first exposure in relation to the risk of breast cancer. Int. J. Epidemiol. 1989; 18: 511-17.

10 Nasca PC, Baptiste MS, Field NA, et al. An epidemiological case-control study of breast cancer and alcohol consumption. Int. I. Epidemiol. 1990; 19: 532-8.

11 Bowlin SJ, Leske MC, Varma A, Nasca P, Weinstein A, Caplan L. Breast cancer risk and alcohol consumption: results from a large case-control study. Int. J. Epidemiol. 1997; 26: 915-23.

12 Longnecker MP, Newcomb PA, Mittendorf R, et al. Risk of breast cancer in relation to lifetime alcohol consumption. J. Natl. Cancer Inst. 1995; 87: 923-9.

13 Swanson CA, Coates RJ, Malone KE, et al. Alcohol consumption and breast cancer risk among women under age 45 years. Epidemiology 1997; 8: 231-7.

14 Hankinson SE, Willett WC. Alcohol and breast cancer: is there a conclusion? Nutrition 1995; 11: 320-1.

15 Männistö S, Pietinen P, Virtanen M, Kataja V, Uusitupa M. Diet and the risk of breast cancer in a case-control study: does the threat of disease have an influence on recall bias? $J$. Clin. Epidemiol. 1999; 52: 429-39.

16 Männistö S, Pietinen P, Pyy M, Palmgren J, Eskelinen M, Uusitupa M. Body-size indicators and risk of breast cancer according to menopause and estrogen-receptor status. Int.J. Cancer 1996; 68: 8-13.

17 Ovaskainen M-L, Valsta LM, Lauronen J. The compilation of food analysis values as a database for dietary studies - the Finnish experience. Food. Chem. 1996; 57: 133-6.

18 Männistö S, Virtanen P, Mikkonen T, Pietinen P. Reproducibility and validity of a food frequency questionnaire in a case-control study on breast cancer. J. Clin. Epidemiol. 1996; 49: 401-9.

19 Willett W. Nutritional Epidemiology, 2nd edn. New York: Oxford University Press, 1998.

20 Van den Brandt PA, Goldbohm A, van't Veer P. Alcohol and breast cancer: results from the Netherlands Cohort Study. Am. J. Epidemiol. 1995; 141: 907-15.
21 Friedenreich CM, Howe GR, Miller AB, Jain MG. A cohort study of alcohol consumption and risk of breast cancer. $\mathrm{Am}$. J. Epidemiol. 1993; 137: 512-20.

22 Gapstur SM, Potter JD, Sellers TA, Folsom AR. Increased risk of breast cancer with alcohol consumption in postmenopausal women. Am. J. Epidemiol. 1992; 136: 1221-31.

23 Graham S, Zielezny M, Marshall J, et al. Diet in the epidemiology of postmenopausal breast cancer in the New York State Cohort. Am. J. Epidemiol. 1992; 136: 1327-37.

24 Holmberg L, Ohlander EM, Byers T, et al. Diet and breast cancer risk: results from a population-based, case-control study in Sweden. Arch. Intern. Med. 1994; 154: 1805-11.

25 Ferraroni M, Decarli A, Franceschi S, La Vecchia C. Alcohol consumption and risk of breast cancer - a multicentre Italian case-control study. Eur. J. Cancer 1998; 34: 1403-9.

26 Royo-Bordonada MA, Martin-Moreno JM, Guallar E, et al Alcohol intake and risk of breast cancer: the Euramic Study. Neoplasma 1997; 44: 150-6.

27 Adelstein A, White G. Alcoholism and mortality. Popul. Trends 1976; 6: 7-13.

28 Adami H-O, McLaughlin JK, Hsing AW, et al. Alcoholism and cancer risk: a population-based cohort study. Cancer Causes Control 1992; 3: 419-25.

29 Uusitalo U, Pietinen P, Leino U. Food and Nutrient Intake Among Adults in East and Southwest Finland - A Dietary Survey of the Finmonica Project in 1982. Publications of the National Public Health Institute No. B1/1987. Helsinki: Government Printing Centre, 1987.

30 Kleemola P, Virtanen M, Pietinen P. The 1992 Dietary Survey of Finnish Adults. Publications of the National Public Health Institute No. B2/1994. Helsinki: Helsinki University Printing House, 1994.

31 Simpura J, Paakkanen P, Mustonen H. New beverages, new drinking contexts? Signs of modernization in Finnish drinking habits from 1984 to 1992, compared with trends in the European Community. Addiction 1995; 90: 673-83.

32 Feunekes GIJ, van't Veer HP, van Staveren WA, Kok FJ Alcohol intake assessment: the sober facts. Am. J. Epidemiol. 1999; 150: 105-12.

33 Colditz GA. Fat, estrogen, and the time frame for prevention of breast cancer. Epidemiol. 1995; 6: 209-11.

34 Holmberg L, Baron JA, Byers T, et al. Alcohol intake and breast cancer risk: effects of exposure from 15 years of age. Cancer Epidemiol. Biomark. Prev. 1995; 4: 843-7.

35 Hiatt RA, Klatsky AL, Armstrong MA. Alcohol consumption and the risk of breast cancer in a prepaid health plan. Cancer Res. 1988; 48: 2284-7.

36 Freudenheim JL, Marshall JR, Graham S, et al. Lifetime alcohol consumption and risk of breast cancer. Nutr. Cancer 1995; 23: 1-11.

37 Harvey EB, Schairer C, Briton LA, et al. Alcohol consumption and breast cancer. J. Natl. Cancer Inst. 1987; 78: 657-61.

38 Dwyer JT, Garnder J, Halvorsen K, et al. Memory of food intake in the distant past. Am.J. Epidemiol. 1989; 130: 103346.

39 Liu S, Serdula MK, Byers T, Williamson DF, Mokdad AH, Flanders WD. Reliability of alcohol intake as recalled from 10 years in the past. Am. J. Epidemiol. 1996; 143 177-86.

40 World Cancer Research Fund and American Institute for Cancer Research. Food, Nutrition and the Prevention of Cancer: A Global Perspective. Menasha: Banta Book Group, 1997. 